Max-Planck-Institut für demografische Forschung

Max Planck Institute for Demographic Research

Konrad-Zuse-Strasse 1 - D-18057 Rostock · GERMANY

Tel +49 (0) 3812081 - 0; Fax +49 (0) 3812081 - 202;

http://www.demogr.mpg.de

MPIDR WORKING PAPER WP 2005-028

SEPTEMBER 2005

\title{
Fertility transition and the progression to third birth in Turkey
}

Sutay Yavuz (yavuz@demogr.mpg.de)

This working paper has been approved for release by: Gerda Ruth Neyer (neyer@ demogr.mpg.de) Deputy Head of the Laboratory of Contemporary European Fertility and Family Dynamics.

(C) Copyright is held by the authors.

Working papers of the Max Planck Institute for Demographic Research receive only limited review. Views or opinions expressed in working papers are attributable to the authors and do not necessarily reflect those of the Institute. 


\title{
FERTILITY TRANSITION AND THE PROGRESSION TO THIRD BIRTH IN TURKEY
}

\author{
Sutay Yavuz
}

\begin{abstract}
During the last two decades, Turkey entered into the last phase of its demographic transition. The latest nationwide Turkey Demographic and Health Survey (TDHS) reveals that the current TFR is close to reproduction level, with a wide range of west-east regional disparity. The purpose of this study is to examine important determinants of third-birth intensities of two-child mothers by applying eventhistory analysis to retrospective survey data. Some of the basic socioeconomic characteristics of women and their first marriages - related to the cultural context of fertility behavior - are investigated with hazard regression models. We demonstrate that the third-birth intensities differ considerably by mother tongue of the woman. Turkish-speaking women who read easily and who were employed and covered by social security before their first marriage had the lowest transition rate from second to third child. In contrast, Kurdish women who could not read and who did not work had the highest third-birth risk. While the fertility decline among Turkish women has been constant for two decades, the fertility remains high among illiterate Kurdish women, who can be classified as laggards in the Turkey's fertility transition.
\end{abstract}




\section{INTRODUCTION}

Demographic transition is a global phenomenon. Partly due to differences in the period of onset of demographic transition and partly due to differences in the rate of the transition, population growth and changes in age profile of the population manifest in different ways. In this respect, the pace of fertility decline in the demographic transition is as important as the fertility decline itself (Casterline, 2001). Faster fertility decline not only brings about smaller population sizes at the end of the demographic transition, but it also contributes to a favorable age composition during its initial phase. This amounts to an economic "demographic gift", which is assumed to have contributed to, for example, East Asia's so-called economic miracle (Bloom and Williamson, 1998).

Fertility behavior is an eminently social behavior; as such, it is influenced by both social context and the decision making of individuals and couples. Most studies on fertility in Turkey have concentrated on quinquennial period aggregate fertility changes. Differences in fertility between subgroups generally have been attributed to socioeconomic differentials. Nevertheless, when social change reduces group differences in socioeconomic characteristics or when such conditions are controlled statistically, discrepancies in fertility behavior between subgroups may remain. The ongoing fertility transition, one of the major demographic issues in Turkey, is in need of better research in order to discover its pace, extent and nature in different societal contexts. The rich body of information provided by demographic surveys can be exploited with new approaches and methods of causal analysis. The aim of this study is to identify different groups in the fertility decline process: the pioneers and the laggards in low-fertility behavior. We use some cultural markers of 'modern' and traditional' traits in the analysis in order to discover what kinds of combinations of characteristics are decisive in the transition process.

The progression from second to third birth is as a critical component of fertility change during the demographic transition process, since the reduction especially of third and higher-order births maintains the fertility decline (Van de Kaa, 1987; Feeney and Wang, 1993). For this reason, the focus of this study is to explore 
important determinants of third-birth intensities of women in Turkey by applying event-history analysis to retrospective survey data.

In Turkey, marriage is almost universal and practically all births occur within marital unions, whether they be civil or religious marriages. Demographic studies usually involve various demographic aspects of marriage, such as mean age at marriage, proportion married, divorce propensity, and the like. However, the linkages between various social aspects of marital unions and subsequent marital fertility behavior are rarely taken into account. In this paper, we examine the impact of marriage characteristics related to the cultural context of third-birth behavior. We expect that a higher influence of traditional and customary traits of marriage, observable at the beginning of the union, would lead to a higher tendency to progress from second parity to a third birth. Conversely, we assume that starting a conjugal union in more egalitarian settings would lessen the propensity to have a third child, due to there being less influence of customary fertility expectations and conservative cultural contexts.

\section{BACKGROUND: TURKEY AND ITS DEMOGRAPHIC TRANSITION}

Turkey has experienced intensive social and economical changes since the early $20^{\text {th }}$ century. The size and the structure of its population have changed along with alterations in society. By providing a more peaceful and secure environment, the foundation of the Turkish Republic in the early 1920s brought about a long-term increase in population. Turkish population trends can be observed in the changes of some basic demographic indicators. The population increased by a factor of five in the last 70 years $^{1}$ (SISa, 2003). The improvements in health services and living standards have brought a steady decline in both child and adult mortality. The Crude Death Rate declined from around 30 per thousand in the 1940s to 7 per thousand at the beginning of the 2000s (SISb, 2003). The second half of the $20^{\text {th }}$

\footnotetext{
${ }^{1}$ The 2000 census reveals that the population size of Turkey was 67.8 million, whereas it was only 13.6 million in 1927. Turkey is among the 20 most populous countries of the world, and it is the most populous country in the Middle East and, after Germany, the second most populous country in Europe. According to projections, her population is currently around 71 million (Population Reference Bureau, 2004).
} 
century also witnessed dramatic declines in fertility rates. In the early 1970s, the Total Fertility Rate (TFR) was about 5 children per woman, whereas current fertility is close to reproduction level (HUIPS, 2004): it is estimated to be 2.2 from the latest 2003 Turkey Demographic and Health Survey (TDHS-2003). As a result, the age structure of the population has been changing rapidly ${ }^{2}$. Since the early 1950s, the country has also had a history of substantial internal and external migration due to extensive urbanization. The urbanization is still profoundly changing the spatial distribution of the population; it is nowadays predominantly concentrated in urban settlements (province and district centers) ${ }^{3}$. Intensive migration between regions, mainly from the east to the west and south, from interior to coastal regions, and from rural to urban areas is important in shaping the contemporary social structure of Turkey.

Several researchers have claimed that Turkey entered the last phase of the demographic transition during the 1980s (SIS 1995; Koray, 1997; Ünalan, 1997). According to some projections, the demographic transition will be completed by the mid $21^{\text {st }}$ century and the Turkish population will remain more or less constant thereafter, at slightly above 95 million inhabitants (SIS, 1995).

The Turkish registration systems have not kept pace with developments, and they therefore do not enable one to provide data for demographic assessment. On the other hand, the country does have a noteworthy history of conducting national censuses and demographic surveys that have been providing data of reasonable quality. The examination of demographic sample surveys, fielded every five years since 1963, has indicated a sustained decline in fertility. In terms of fertility transition, there is no uniformity in change over the country. Regional disparities in Turkey have always been a central theme in demographic studies as well as in the wider social-science literature. Internal heterogeneity across the country is inevitable due to its large geographical area and population size. Different sections of the population have been affected by social and cultural changes in different ways and at varying paces. The trends in urban and regional fertility indicate that

\footnotetext{
${ }^{2}$ One-third of the population is under 15 years of age, while the proportion $65+$ comprises only 6 percent according to the 2000 Census results (SISa,2003). The increase in the population of ages 15-64 and $65+$ will proceed in the next years while the population size of the youth will stabilize. According to United Nations estimates (medium variant), the share of the elderly population will reach around 10 percent of the Turkish population by 2025. It is also expected that the median age will rise to 34 years in 2025 (UN, 1999).
} 
some parts of the population are already experiencing below-replacement fertility. According to the TDHS-2003, the greatest contrast in fertility is between the eastern region and the rest of the country. TFR is 3.65 for women in eastern Turkey, which is about one-and-a-half children more than for women elsewhere in the country.

In short, regional disparities along a west-east divide are important characteristics of Turkey. The richest regions are located in the western part of the country, while the poorest ones are in the eastern part. The richer regions have substantial shares of production and employment in manufacturing and services, but in other regions agriculture is still the most important source of income and employment. A contrast between 'modern' and 'traditional' cultural features is maintained along this scale of regional diversification. Though policies and development strategies focus on minimizing social and economic differences among the regions, satisfactory achievements have not been reached so far.

The educational level of individuals shows a great deal of variance by rural-urban residence, region, sex, and age. Younger generations attain higher levels of education. TDHS-1993 and TDHS-2003 reveal that the proportion of women aged 15 to 49 that have completed at least the second level of primary school increased from 15 percent in 1993 to 24 percent in 2003. Fertility differentials among women with different educational backgrounds are striking; the mean number of children ever born (a measure of completed fertility) among women aged 40 to 49 without formal education is 5 , while the same figure is only 2 for women at the same ages who have completed high school or higher level education.

\section{METHODOLOGY, DATA AND VARIABLES IN OUR THIRD-BIRTH STUDY}

The progression to a third birth, as with any other type of life-course transition, does not occur at random or in isolation, but in relation to certain structures. The method used in our analysis should be able to ascertain how and to what extent the transition rate to the third parity is systematically related to a woman's own

\footnotetext{
${ }^{3}$ According to the 2000 Census 65 percent of the population in Turkey lives in urban areas.
} 
background and marriage characteristics. Because of the retrospective nature of the TDHS-98, some birth intervals had not been closed by the time of survey, so information about the duration as a two-child parent was incomplete for these cases. Because of this type of right-censored data, ordinary regression models cannot sufficiently analyze causal relationships of third births. Various methods and measurements for analyzing censored survival data are proposed in the literature; e.g. the Kaplan-Meier survival curve, the life table, and the Cox proportionalhazards model (Kleinbaum, 1996). The simpler descriptive methods, such as the life table and the Kaplan-Meier method can handle the right-censoring problem but cannot take into account the simultaneous effects of other variables.

One appropriate way of analyzing such data is to construct (piecewise constant) proportional-hazard (or intensity-regression) models. The hazard-regression models belong to the group of event-history models dealing with rates of transition from one social status to another. Transition-rate models have been defined as "general statistical techniques through which one can analyze how the transition rate depends on a set of covariates" (Blossfeld and Rohwer, 2002). In other words, the transition rate ${ }^{4}$ is considered a function of some covariates and is assumed to be related to other social processes.

The risk of a third birth, or the transition rate from second to third parity, is estimated with respect to some basic background attributes of women and main characteristics of her first marriage. A relative risk of 1.00 for the level of a covariate indicates that the estimated third-birth risk is the same as that of the reference group of the same covariate. A relative risk estimated to be greater (smaller) than 1 indicates a higher (lower) third-birth risk than for the reference category. A woman's third-birth risk is defined as the probability that she will experience a third birth the next month, given her individual and marriage characteristics and given that she has not had such a birth by the beginning of the month. Risks are assumed constant within each time interval but may vary across such intervals (the hazard rates are piecewise constant).

\footnotetext{
${ }^{4}$ The transition rate also is labeled hazard rate, intensity rate, failure rate, risk function in different studies.
} 
The data used in this study originates from the 1998 Turkish Demographic and Health Survey (TDHS-98), the second survey in a series of three national demographic and health surveys conducted in the last ten years. The TDHS-98 was designed to provide information on fertility levels and trends, infant and child mortality, family planning, and mother and child health from a nationally representative sample survey. The survey was fielded between August and November 1998. Interviews were carried out in 8,059 households, with 8,576 women and 1,971 husbands of currently married women. All women aged 15 to 49 who were present in the household the night before the interview or who generally lived in the household were eligible for the survey. The sample for the study was designed to provide an estimation of demographic and health indicators for the nation as a whole, for urban and rural areas, and for the five major regions (the west, south, center, north and east). A weighted, multi-stage, stratified cluster sampling approach was used in the selection of the sample.

Even though the survey included a wide range of retrospective questions on birth histories and contraceptive usage of the women, most background characteristics were not collected with individual life histories. That is, most useful attributes of women, such as education, migration, employment, family cycle etc., were obtained only for their situation at the time of the survey. Thus, it was almost impossible to examine these variables in conjunction with preceding births and to regard them as explanatory (time varying) variables.

We include women in a first marital union at the time of the interview in our analysis. There are two reasons why this is reasonable. First, the data reveals that only 3.1 percent of all ever-married women had more than one marriage. The vast majority of Turkish women complete their reproductive career in their first marriage. Secondly, in the questionnaire, higher-order marriages were neglected during the recording of marriage and birth-history information. Since we do not have information on the termination date of first marriages and the beginning of second ones, it is not possible to examine births and higher-order marriages in conjunction. 
There are 4,273 two-child mothers ${ }^{5}$ included in our third-birth study. These are women who were in their first union and who had had at least two births at the time of the survey. Cases with twin births at the second birth were excluded from the analysis. The observation starts with the birth date of the second child and ends with either the birth date of a third child or the survey date. Cases are right censored if no third-birth event is observed before the survey in 1998.

We employ seven time-fixed and two time-varying covariates in our study. The first background variable is mother tongue of woman with two levels: namely, 'Turkish' and 'Kurdish and dialects'. Several other languages combined into an 'other' category ${ }^{6}$ were included in preliminary modeling. This latter category only comprises some 4 percent of two-child mothers and their third-birth behavior does not deviate much from the overall pattern in Turkey. In order to simplify the presentation, this category is not included in subsequent analyses and tabulations.

Identifying an ethnic group is not a straightforward task, and it largely depends on the historical and cultural context. There are a number of approaches to identifying ethnic groups but the language of a community is one principal marker (Weber, 1961). It is not practical to include all possible questions helpful to identifying ethnic groups in a TDHS survey. Thus, ethnic groups are classified as those who declared a particular language as mother tongue. The Turkish and Kurdish language groups comprise together 96 percent of all cases; four out of five women in the study declared Turkish as their mother tongue. There are not many fertility studies that have used ethnic background directly as a variable in Turkey. However, previous studies have stated briefly that Kurdish women in Turkey have higher fertility rates than Turkish-speaking women. They claim that, when different demographic factors are considered, Turks and Kurds can be seen as actors in different demographic regimes, at different stages of the demographic and health transition (Dundar, 1998; Hancıoğlu and Koç, 1999; Hancığ̆lu and others, 2000). On the other hand, Tasiran (1997 and 2000) applied dynamic transition-rate models on TDHS-1993 data and asserted that "ethnicity is important but not as it is thought

\footnotetext{
${ }^{5}$ The unweighted case number is 4338 .

${ }^{6}$ Arabic, Armenian, Circassian, Georgian, Hebrew, Persian, Greek, Laz and East and West European languages. The largest of these minorities by far, with around 60 percent, consists of women whose mother tongue is Arabic.
} 
and widely accepted; Kurdish women do not have higher fertility than Turkish women."

The age patterns of fertility and total fertility (TFR) estimated from the 1998 TDHS for the two main language groups are presented in Table 1. Both age patterns in fertility and TFR measures differ between the two ethnic groups. From 1995 to 1998, the Kurdish period TFR is 1.9 times higher than the TFR of Turkish-speaking women. For Turkish-speaking women, fertility is concentrated at ages 20 to 34, while, for the Kurdish group, the reproductive period covers a wider age span. Since fertility is highest in the eastern region of Turkey, where the Kurdish population is most prevalent, the figures are given separately for this region as well. The overall level is higher than the averages for Turkey as a whole but differences between language groups are quite similar; Kurdish women have much higher fertility than Turkish women in each age group.

Table 1. Age Specific Fertility Rates ${ }^{1}$ (ASFR; per thousand) and Total Fertility (TFR) by Ethnic Groups in Turkey, 1995-98

\begin{tabular}{crrrrr}
\hline \hline & \multicolumn{2}{c}{ Turkey } & \multicolumn{3}{c}{ Eastern Turkey } \\
Age Group & \multicolumn{1}{c}{ Turks } & Kurds & Total & Turks & Kurds \\
\hline $15-19$ & 54.1 & 75.7 & 59.8 & 68.2 & 68.6 \\
$20-24$ & 152 & 213.1 & 163.3 & 172 & 248.8 \\
$25-29$ & 134.5 & 234.1 & 150 & 159.5 & 251.8 \\
$30-34$ & 77.6 & 175.9 & 93.1 & 90.5 & 211.7 \\
$35-39$ & 29.2 & 120.3 & 41.9 & 61.9 & 140.5 \\
$40-44$ & 9.3 & 35 & 13.2 & 34.7 & 47.6 \\
$45-49$ & 0.7 & 0 & 0.6 & 0 & 0 \\
& & & & & \\
TFR & $\mathbf{2 . 2 9}$ & $\mathbf{4 . 2 7}$ & $\mathbf{2 . 6 1}$ & $\mathbf{2 . 9 3}$ & $\mathbf{4 . 8 4}$ \\
\hline \hline
\end{tabular}

Rates are calculated for the 36 months preceding the survey date.

Next, the age of the mother at the second birth is included in the analysis, with four different age categories. We expect that women who had a second child early in their reproductive career will have a higher transition rate to a third birth. Early age at second birth is also related to early age at marriage. 
Literacy level is a commonly used socioeconomic indicator. In this study, it is included in the analysis with three levels: 'reads easily', 'reads with difficulty' and 'cannot read'. As for other covariates, literacy level refers to the ability at the date of the survey. It is assumed that reading ability is obtained before the first marriage and/or second birth and is not prone to significant change subsequently. Compared to employing educational-attainment level at the time of the survey, literacy level is likely to be less problematic as regards anticipatory problems (Hoem, 1996) in the event-history analysis.

The premarital working experience of women is another socioeconomic indicator. The working experience of women was not collected for the whole life course, but refers only to the situation before marriage. The variable reflects socio-cultural traits of women. Work experience before marriage may also be related to the age at marriage, which in turn affects marital fertility. In addition, work experience, especially if it occurs outside the domestic sphere, provides the opportunity to expose oneself directly to the outside world. Women who "had not worked before marriage' and who 'had worked without social security' are categorized into one common level since those who had been employed without being covered by social security predominantly worked as unpaid family labor on the familial agricultural land or as some other kind of agricultural worker. In contrast, women who had been employed and covered by social security had worked in areas with an occupational ability, e.g. as teacher, nurse, factory worker, etc. The two types of working experiences are expected to have different impacts on reproductive behavior. Almost six out of ten women in the study did not work at all before their first marriage. Previous studies show that women belonging to the non-working group have considerably higher fertility than others (Ergöçmen, 1997).

The experience of being employed and having a higher level of educational attainment allows women to be less dependent on their husbands and extended family. We argue that, if a woman has a greater degree of independence, this might decrease her third-birth intensity. Such a relationship between the education and work experience of women and their fertility may not be generalized to all sociocultural and economic contexts; studies about the transition to a third birth in some European countries, such in Sweden, present the opposite effect of educational attainment (Hoem et al., 2001) on third-birth risks. 
The universality of marriage in Turkey has been demonstrated in several studies (Ergöçmen, 1997; HUIPS 1994, 1999). As a social norm, women are expected to get married no later than in their late twenties and eventually almost all women marry. For the TDHS-1998, only 6.5 percent of women aged 30 to 34 at the survey date were not or had not been married. Several cultural and religious norms have an influence on family-formation patterns. Some attributes of the family-formation process can be used to categorize the unions, in broad terms, as "traditional" or "modern". In this manner, three covariates are employed in the present study. First, payment of 'bride's money' to the family of the bride at marriage formation is included as an independent variable. The bride's money can be in cash or kind; the latter type is more widespread. The payment of brides' money, regardless of whether it has a nominal or symbolic value, is considered a reflection of patriarchal ideology that is likely to reduce the status of the wife and also of female children. One of the main functions of this type of payment is to compensate for the loss of a laborer from the bride's family (Timur, 1972). Also, it is a social phenomenon reflecting the price of beauty and skill of young women and it represents the prosperity of the groom's family. Concerning its economic and social aspects, this type of marriage can be regarded as more closed and conservative in terms of family relations. In the data, one out of four marriages was established with the payment of bride's money. The custom is most pervasive in the eastern region, where it occurs in 55 percent of all marriages. This custom is more widespread in rural areas, where the economic contribution of women in agriculture is high, than in urban areas.

Secondly, the decision-making practice at the formation of the marital union is considered. In Turkey, the mutual consent of the spouses and the immediate family is most common in the formation of a family. The arrangement of marriage by the families is common practice. Nevertheless, in most cases, the bride and groom are both also asked for their consent. It is also common that the decision to form a marital union is first made by the couple, who subsequently seeks the parents' consent. In our data, only 35 percent of all marriages are established solely by the couple's decision, i.e. without their seeking their parents' consent. In the remaining cases, the parents' decision was involved in the formation process to some extent. It is legitimate to set up the two juxtaposed general categories of "modern" and 
"traditional" marriages as concerns the decision-making process. The arrangement of the marriage solely by the parents can be seen as a particular reflection of conservatism in the lifestyle. Such unions are more prone to the intervention of members of the extended family, which is likely to affect the subsequent fertility behavior as well. Our covariate has three levels: arrangement 'by themselves', 'by families' and 'other'. The 'other' category refers to the situation where both couple and family consent plays a role in the marriage formation. It can thus be viewed as an intermediate variant in terms of the level of traditionalism.

Thirdly, a characterization of the family type at the beginning of the marriage is included in the analysis. Most newly formed marriages in Turkey are established in an extended family environment: according to the data, this type of beginning comprises 65 percent of marriages. The newly married couple usually does not form a separate household at the beginning of their marriage but resides in the husband's parental household. This can be seen as another reflection of patriarchal ideology. One expects to find higher third-birth risks for women who began conjugal life in an extended household as compared to women who started marital life in a neo-local settlement.

Finally, we apply two time-varying covariates for calendar-year period and the duration elapsed since the second birth. The first time-varying covariate is intended to capture the influence of changes in the socio-political environment on third-birth intensities. We use four time periods in this categorization. From the foundation of the republic to the mid-1960s, Turkish governments to some extent implemented pronatalist policies. The Population Law of 1965 marked a policy change in the opposite direction and previous restrictions on contraceptives and abortions were somewhat liberalized. In 1983, the Population Planning Law was revised again. More liberal comprehensive regulations were implemented with, for example, abortions being possible up to the tenth week of pregnancy and the possibility of voluntary surgical contraception (SPO, 1993). Also, the last two TDHS studies reveal that there was an increasing shift from the 1980s to the 1990s towards more modern contraceptive usage (HUIPS 1994, 1999). This shift in contraceptive behavior is likely to decrease the progression risk of a third birth after 1983 .

The period factor also captures other changes in Turkish society. The economy has undergone a radical transformation from an agricultural base to industrial and 
service activity, particularly within the last two decades. This process is likely to have inhibited fertility in general and third- and higher-order births in particular, especially for women in economically more developed regions. The last two decades also witnessed other changes in the economic structure of the country. The economic strategy before 1980 was mainly based on 'Five-Year Development Plans' in which protectionism was the dominant economic policy. In contrast, at the beginning of the 1980s, Turkey began a series of reforms designed to shift the economy from this statist system to a private-sector free-market model. The economic growth has been high ${ }^{7}$ but also very volatile; sharp recessions and financial crises occurred particularly in the last period of this study. In addition, the rapid economic development contributed to growing differences and disparities between rich and poor segments of society, and rich and poor regions of the country. The social development has not paralleled the economic growth performance (Human Development Report, 1996). Existing disparities within the country have been sustained and economic inequality cuts across regions, social groups, gender, age and urban-rural residence (UNDP, 2005).

The last two decades, 1984 to 1999, witnessed a harsh armed conflict between the illegal armed Kurdish Workers' Party (PKK) and Turkish armed forces. A substantial number of villages and adjacent arable lands were abandoned during the period, especially between 1989 and 1992, in east and southeast Anatolia. The Kurdish population living in villages and pastures was often displaced by both the activities of terrorist movements and the struggle of Turkish armed forces against terrorist groups. Today the majority of these displaced people are living in poverty in urban areas throughout the country. In most circumstances, abrupt displacement disrupts traditional familial and community bonds. It is a traumatic event and, for individuals, displacement may cause feelings of insecurity and anxiousness. For this reason, the displacement process is likely to have affected third-birth risks of Kurdish women having experienced this migration process.

The basic time variable of the hazard regression is the number of months elapsed since the birth of the second child. The duration is measured in months and categorized into five intervals, covering ages from 0 to 18.5 years.

\footnotetext{
${ }^{7}$ GDP per capita increased continuously. The mean value of GDP in USD, by period, is as follows; 1975-1982: 2109, 1983-1987: 3379, 1988-1992: 4589, 1993-1998: 5902. See Appendix.
} 
Our model fitting is conducted in a stepwise procedure. First, individual demographic characteristics (mother tongue and age of the woman at the second birth) and the time-varying variables are included in the model. Secondly, covariates on socioeconomic development (literacy and work before marriage) are introduced. Lastly, the groups of covariates that represent cultural traits of the marriages are involved in a third model. For empirical analysis, the software package Ev-HA (version 0.32, Max Planck Institute for Demographic Research) is used to fit intensity-regression models. The model parameters, produced as maximum-likelihood estimates, are presented in the form of relative risks. In the present analysis, the following full multiplicative main-effects model is estimated:

$$
h(t)=a_{k} b_{l} c_{m} d_{n} e_{o} f_{p} g_{r} h_{s} i_{t}
$$

where $h(t)$ is the third-birth intensity that depends on various levels of factors, where $a$ is the basic time factor, the duration since the birth of second child, $b$ is the mother tongue, $c$ is the calendar period, $d$ is age category of the mother at her second birth, $e$ is literacy level of the woman, $f$ is working status before marriage, $g$ is whether bride's money was paid before marriage, $h$ indicates whether the marriage was arranged, and $i$ is whether the marital life of the woman started in a neo- or a patri-local settlement. The variables are grouped into categorical levels, indexed by $\mathrm{k}, \mathrm{l}, \mathrm{m}, \mathrm{n}, \mathrm{p}, \mathrm{r}, \mathrm{o}, \mathrm{s}$ and $\mathrm{t}$.

\section{THIRD BIRTHS IN TURKEY}

Model 1of Table 2 provides a first overview of relative third-birth risks. We note a considerable difference in risk between the categories of "mother tongue of the woman', 'calendar period' and 'age of mother at second birth'. The highest progression risk among the mother-tongue groups is observed for Kurdish women; they have more than double the progression risk of Turkish-speaking women. The first level of the 'period' covariate has the highest progression risk and then the risk diminishes at each subsequent level. In the last period, 1994 to 1998, the risk is almost 70 percent lower than for the period before 1983. The model also reveals that, if the mother has the second child later in the reproductive time span, then the risk of a subsequent birth diminishes. 
Table 2. Relative risks of third birth, by characteristics of two-child mothers in Turkey

\begin{tabular}{|c|c|c|c|}
\hline Factors - Levels & Model 1 & Model 2 & Model 3 \\
\hline Duration since second birth & **** & **** & **** \\
\hline$<1.5$ year & $1\left(13.91^{\wedge}\right)$ & $1\left(10.54^{\wedge}\right)$ & $1\left(6.93^{\wedge}\right)$ \\
\hline $1.5-2.49$ years & 2.80 & 2.82 & 2.84 \\
\hline $2.5-3.99$ years & 2.51 & 2.58 & 2.61 \\
\hline $4.0-5.99$ years & 2.06 & 2.14 & 2.18 \\
\hline $6.0-18.5$ years & 0.83 & 0.84 & 0.87 \\
\hline Age at second birth & $* * *$ & $* * *$ & $* * *$ \\
\hline-20 & 1 & 1 & 1 \\
\hline $21-25$ & 1.69 & 0.74 & 0.77 \\
\hline $26-30$ & 0.42 & 0.48 & 0.51 \\
\hline $31+$ & 0.28 & 0.35 & 0.37 \\
\hline Mother tongue & *** & $* * *$ & $* * *$ \\
\hline Turkish & 1 & 1 & 1 \\
\hline Kurdish & 2.21 & 1.60 & 1.52 \\
\hline Calendar period & **** & $* * *$ & $* * *$ \\
\hline-1982 & 1 & 1 & 1 \\
\hline $1983-1987$ & 0.66 & 0.78 & 0.81 \\
\hline $1988-1992$ & 0.45 & 0.59 & 0.61 \\
\hline $1993-1998$ & 0.32 & 0.46 & 0.48 \\
\hline Literacy & & $* * *$ & $* * *$ \\
\hline Reads easily & & 1 & 1 \\
\hline Reads with difficulty & & 1.47 & 1.35 \\
\hline Cannot read & & 1.83 & 1.66 \\
\hline Work experience & & $* * *$ & ** \\
\hline Yes, with social security & & 1 & 1 \\
\hline No or without social security & & 1.85 & 1.59 \\
\hline Bride's money & & & $* * *$ \\
\hline Not Paid & & & 1 \\
\hline Paid (in cash or kind) & & & 1.27 \\
\hline Marriage arrangement & & & $* * *$ \\
\hline By couple & & & 1 \\
\hline By families & & & 1.21 \\
\hline Other & & & 1.11 \\
\hline Family type & & & $* * *$ \\
\hline Nuclear family & & & 1 \\
\hline Extended family & & & 1.30 \\
\hline Log-likelihood & -13194.4 & -13077.6 & -13062.3 \\
\hline
\end{tabular}

^Absolute risk for first duration level, per 1000 mother months

Significance test of factors: $\quad{ }^{*} 0.05 \leq \mathrm{p} \leq 0.1 \quad{ }^{* * *} 0.01 \leq \mathrm{p} \leq 0.05 \quad{ }^{* * * *} \mathrm{p} \leq 0.01$ 
The risk difference between women from the two mother-tongue groups diminishes when socioeconomic covariates are included in the model (Model 2). Nevertheless, Kurdish women still have 60 a percent higher third-birth risk. Women who cannot read and those who can read only with difficultly have higher progression risks than women who can read easily. Those who cannot read have an 83 percent higher progression risk than those who read easily. The latter group is likely to consist of women who had higher educational attainment: secondary school and above. The findings are consistent with recorded fertility differences by educational level of women in Turkey.

Interaction effects of covariates used in Model 2 demonstrates how progression risks are dependent on different combinations of levels of these covariates. The first interaction model (Table 3) shows that the third-birth risk of Kurdish women started to decrease a decade later than that of Turkish women; the risk for the former group declined noticeably only after 1988 to 1992. For Turkish-speaking women a continual decrease is observed for the whole study period.

Table 3. Relative risk of third birth, by calendar period and mother tongue, controlling for the other factors in Model 2 of Table 2. Risks relative to first calendar period for each language group.

\begin{tabular}{lcccc}
\hline \hline & $\mathbf{- 1 9 8 2}$ & $\mathbf{1 9 8 3 - 8 7}$ & $\mathbf{1 9 8 8 - 9 2}$ & $\mathbf{1 9 9 3 - 9 8}$ \\
\hline \multicolumn{2}{l}{ Interaction: Mother Tongue * Period } \\
& 1 & & & \\
Turkish & 1 & 1.08 & 0.94 & 0.63 \\
$\quad$ Kurdish & 1 & &
\end{tabular}

The second interaction involves age of mother at second birth and mother tongue (Table 4). The effect of age at second birth is very different for the two ethnic groups. Having a second birth at a relatively old age is inversely related with having a third child among Turkish women. For Kurdish women, there is a very loose relationship of this kind. Only after age 30 is there a significant decrease in risk. This is also consistent with the ASFR pattern presented in the Table 1. 
Table 4. Relative risk of third birth, by age of mother at second birth and mother tongue, controlling for the other factors in Model 2 of Table 2. Risks relative to first age category for each language group.

\section{$\begin{array}{llll}-20 & 21-25 & 26-30 & 31+\end{array}$}

\begin{tabular}{lrlll}
\hline Interaction: Mother Tongue * Age at Second Birth & \\
& 1 & 0.72 & 0.44 & 0.34 \\
Turkish & 1 & 0.91 & 0.91 & 0.52 \\
Kurdish & & & & \\
\hline${ }^{* * * *} \mathrm{p} \leq 0.01 \chi^{2}(\mathrm{df}: 3)=16.99$ & & & &
\end{tabular}

The third interaction involves literacy and period (Table 5). The progression risk decreases after 1983, regardless of the literacy level of the women but with different paces. The slowest change occurred for women who are not able to read. Note that illiteracy is much more widespread among the Kurdish women whose patterns of decrease are also similar.

Table 5. Relative risk of third birth, by literacy and period, controlling for the other factors in Model 2 of Table 2. Risks relative to first calendar period for each literacy group.

\section{$\begin{array}{llll}-1982 & 1983-87 & 1988-92 & 1993-98\end{array}$}

\section{Interaction: Literacy * Period ${ }^{* *}$}

$\begin{array}{lllll}\text { Reads easily } & 1 & 0.79 & 0.52 & 0.44 \\ \text { Reads with difficulty } & 1 & 0.63 & 0.52 & 0.45 \\ \text { Cannot read } & 1 & 0.87 & 0.80 & 0.56 \\ { }^{* * *} \mathrm{p} \leq 0.05 \chi^{2}(\mathrm{df}: 6)=16.78 & & & & \end{array}$

A three-way interaction of mother tongue, literacy and period yields further detail to patterns in third-birth decline by the calendar periods we cover (Table 6). This is done by comparing third-birth risks for different groups with the risk of the same group in the calendar period of 1982 and preceding years. For Turkish-speaking women, a sustained decrease in third-birth fertility in the last two decades is obvious in all categories. Also, the fertility decline does not differ significantly between different groups. In contrast, patterns do differ between various categories 
of Kurdish women. For Kurdish women who are able to read at least to some extent, the third-birth risk begins to decline in the period from 1988 to 1992. Kurdish women who were unable to read are clearly the most resistant group to fertility change. Their third-birth risks did not start to diminish until the last period.

One explanation for the different pace in fertility decrease of the two main ethnic groups in Turkey could be that it is related to the settlement pattern of women. Turkish-speaking women are predominantly located in western regions and more urbanized areas. These are the most modern parts of the country. They are thus more likely to have been exposed to more 'modern' fertility norms and to have access to modern contraceptives. By contrast, Kurdish women are to a larger extent subject to the more traditional values and ineffective contraception methods that prevail in rural conditions in the east of the country.

Table 6. Relative risk of third birth, by different combinations of mother tongue, literacy and period, controlling for the other factors in Model 2 of Table 2. Risks relative to first calendar period for each combination of literacy and mother tongue.

\section{$\begin{array}{llll}-1982 & 1983-87 & 1988-92 & 1993-98\end{array}$}

\begin{tabular}{|c|c|c|c|c|}
\hline \multicolumn{5}{|c|}{ Interaction: Mother Tongue $*$ Literacy $*$ Period $^{* * *}$} \\
\hline Turkish * Reads easily & 1 & 0.77 & 0.52 & 0.43 \\
\hline Turkish $*$ Reads with difficulty & 1 & 0.59 & 0.49 & 0.38 \\
\hline Turkish $*$ Cannot read & 1 & 0.74 & 0.63 & 0.52 \\
\hline Kurdish $*$ Reads easily & 1 & 1.25 & 0.60 & 0.39 \\
\hline Kurdish $*$ Reads with difficulty & 1 & 0.90 & 0.63 & 0.64 \\
\hline Kurdish $*$ Cannot read & 1 & 1.05 & 1.02 & 0.64 \\
\hline
\end{tabular}

In the final model of Table 2, Model 3, the remaining covariates related to cultural aspects of marriage are included as well. The impacts of these covariates are in accordance with the theoretical framework of our study. For each of these covariates, the level related to more 'modernized' behavior is chosen as the reference category and has the lowest third-birth risk. Women whose family did not 
receive bride's money, who herself made the marriage decision together with her husband, and who began the marital union in a nuclear family had lower progression risks than women who married in a more customary manner. Women who married with the payment of bride's money have an almost 30 percent higher progression risk to a third birth than women who married without such a payment. Similarly, women who had less autonomy in the decision process of marriage have a 10 to 20 percent higher risk, and women who started conjugal life in an extended settlement have a 30 percent higher third-birth risk when the effect of all other factors are controlled for.

The effect of marriage attributes on having a third birth is related to calendar period and mother tongue, as demonstrated in Table 7. A close inspection reveals, for example, that Kurdish women who married with traditional attributes had a slight increase in third-birth risks from the period before 1983 to that of 1983 to 1987.

Another impression from the interactions of marriage attributes with ethnicity and calendar period is that Kurdish women who married in more traditional ways seem to constitute the most lagging groups as concerns fertility decline in Turkey. Contrary to general trends, third-birth fertility is maintained longer at a relatively high level for Kurdish women with such attributes. The decline in third-birth fertility of these women is not evident until in the second half of the 1990s. In contrast, for Turkish women the decline in progression risks is much less dependent on their marriage characteristics. Indeed, by the end of our study period, third-birth risks have declined more or less to the same extent for those who married in modern and traditional manners. 
Table 7. Relative risk of third birth, by different combinations of mother tongue, calendar period, and each of the factors bride's money, family type and marriage arrangement, controlling for the other factors in Model 3 of Table 2. Risks relative to first calendar period for each combination of marriage characteristic and mother

$\begin{array}{llll}-1982 & 1983-87 & 1988-92 & 1993-98\end{array}$

\begin{tabular}{|c|c|c|c|c|}
\hline \multicolumn{5}{|c|}{${ }^{1}$ Interaction: Mother tongue $*$ Bride's money $*$ Period $^{* * *}$} \\
\hline Turkish $*$ Not paid & 1 & 0.74 & 0.55 & 0.44 \\
\hline Turkish $*$ Paid (in cash or kind) & 1 & 0.72 & 0.47 & 0.41 \\
\hline Kurdish $*$ Not Paid & 1 & 0.87 & 0.58 & 0.45 \\
\hline Kurdish * Paid (in cash or kind) & 1 & 1.16 & 1.20 & 0.72 \\
\hline \multicolumn{5}{|c|}{${ }^{2}$ Interaction: Mother tongue $*$ Family type $*$ Period $^{* * *}$} \\
\hline Turkish $*$ Nuclear family & 1 & 0.59 & 0.61 & 0.40 \\
\hline Turkish $*$ Extended family & 1 & 0.78 & 0.49 & 0.45 \\
\hline Kurdish * Nuclear family & 1 & 0.95 & 0.76 & 0.64 \\
\hline Kurdish $*$ Extended family & 1 & 1.12 & 0.99 & 0.63 \\
\hline \multicolumn{5}{|c|}{${ }^{3}$ Interaction: Mother tongue $*$ Marriage arrangement $*$ Period $^{* * *}$} \\
\hline Turkish $*$ Couple & 1 & 0.57 & 0.44 & 0.39 \\
\hline Turkish * Family & 1 & 0.76 & 0.55 & 0.45 \\
\hline Turkish $*$ Other & 1 & 0.95 & 0.56 & 0.35 \\
\hline Kurdish $*$ Couple & 1 & 1.11 & 0.70 & 0.59 \\
\hline Kurdish * Family & 1 & 1.06 & 1.00 & 0.62 \\
\hline Kurdish $*$ Other & 1 & 2.38 & 1.03 & 0.77 \\
\hline $\begin{array}{l}* * * \mathrm{p}<0.01 \chi^{2}(\mathrm{df}: 10)=34.16 \\
* * * \mathrm{p}<0.01 \chi^{2}(\mathrm{df}: 10)=40.27 \\
* * * \mathrm{p}<0.01 \chi^{2}(\mathrm{df}: 17)=34.86\end{array}$ & & & & \\
\hline
\end{tabular}

\section{CONCLUSIONS}

In recent decades, Turkey has experienced rapid changes in its demographic structure. This has occurred together with transformations in its social, political, and economic life. Changes in its social life appear in areas such as the liberation of social and political life, internal migration and urbanization, extension of a free market economy, attempts to integrate into the European Union, etc.. These changes, which are likely to carry on in the near future, have had profound effects on individuals' lives. Fertility dynamics are affected and are in movement as well. Today, the demographic profile of the country is manifested in its young age structure. The prospective result of rapid fertility decrease and the completion of 
Turkey's demographic transition indicate, however, that Turkey will soon face an aging of its population.

In this study, we estimated relative risks of third births by demographic and socioeconomic characteristics of two-child mothers and by various attributes of their marriages. All factors were related to third-birth risks, and our study allowed us to gain further insights into the specificities of the fertility transition in Turkey. We found, for example, that Turkish women who read easily and who were employed and covered by social security before their first marriage had the lowest transition rate from the second to a third child. In contrast, Kurdish women who could not read and who did not work with social-security coverage had the highest third-birth risk.

Marriage characteristics related to the degree of traditionalism or modernity in family lifestyles have an influence on the fertility process. The effect of such marriage attributes has not evolved in the same way over calendar time for the two main ethnic groups in Turkey. For Turkish-speaking women the decline in thirdbirth risks has taken place at a relatively similar pace for those who married in a traditional manner or in more modern ways. In contrast, customary marriage behavior has managed to support the high fertility of Kurdish women much longer. These groups did not experience declines in third-birth fertility until the very last decade of our study.

The results can be seen as supportive of the main arguments generally presented concerning the demographic transition and modernization theory. The segments of the population that have been more integrated into modernization and urbanization trends are changing their fertility behavior more rapidly. The educational composition of the population is one predictor of fertility change, and those who have only a low level of education can be viewed as laggards in the fertility transition (Bongaarts, 2003). We equated education with degree of literacy and our analysis supports this argument; those who cannot read are laggards in the fertility transition in Turkey. We also showed that several other cultural factors are of importance and that it is fruitful to consider a wider spectrum of such variables in fertility studies than is usually the case. 
Evidently, different segments of the population change their behavior at different paces. There are large social disparities in Turkey and these are reflected in fertility differentials as well. The difference in the pace of fertility decline is also evident when we compare the fertility transition of the two main ethnic groups in Turkey. The fertility dynamics of Kurdish parents is an important factor in determining when and how the demographic transition in Turkey will be completed. For future research, it would be interesting to study in more depth the question as to which possible cultural, political, and economic factors have led Kurdish women in Turkey to display a delayed fertility decline.

As an increasing proportion of couples acknowledge replacement fertility as an optimal level for their own reproductive lives, the final stage of the fertility transition is likely to materialize. For Turkey, we can see that modernization, industrialization, urbanization, and the diffusion of urban-type norms make crowded and complex household types less feasible to maintain. Increasing educational standards and postponement of marriage allow for an increasing proportion of women to be involved in market-centered economic activity. All these trends lead to a higher propensity to establish smaller and less extended families. The present study shows that even the most resistant group to fertility decline showed the beginnings of a decrease in third-birth risks in the late 1990s. This implies that we can expect further declines in aggregate Turkish fertility also in the near future.

\section{ACKNOWLEDGEMENT}

This study was prepared at the International Max Planck Research School of Demography during my stay as a winter fellow in the winter semester 2004/05. I am particularly grateful to Dr. Gunnar Andersson for very insightful comments and suggestions on this work and for editorial advice. In addition, I thank Karl Brehmer for the final language editing. 


\section{APPENDIX}

Table A1: Trends in Human Development Indices for Turkey, 1980-98

\begin{tabular}{cccccccc}
\hline \hline & $\begin{array}{c}\text { Life } \\
\text { expectancy at } \\
\text { birth (years) }\end{array}$ & $\begin{array}{c}\text { Adult literacy } \\
\text { rate (\%) age } \\
\text { 6 and above }\end{array}$ & $\begin{array}{c}\text { GDP per } \\
\text { capita PPP in } \\
\text { USD }\end{array}$ & $\begin{array}{c}\text { Life } \\
\text { expectancy } \\
\text { index }\end{array}$ & $\begin{array}{c}\text { Education } \\
\text { index }\end{array}$ & $\begin{array}{c}\text { GDP } \\
\text { development }\end{array}$ & $\begin{array}{c}\text { Human dev. } \\
\text { index (HDI) }\end{array}$ \\
\hline \hline 1980 & 61.9 & 68.7 & 2,252 & 0.615 & 0.628 & 0.520 & 0.588 \\
1981 & 62.3 & 69.7 & 2,542 & 0.622 & 0.635 & 0.540 & 0.599 \\
1982 & 62.6 & 70.8 & 2,724 & 0.627 & 0.647 & 5.552 & 0.609 \\
1983 & 63.0 & 71.9 & 2,914 & 0.633 & 0.664 & 0.563 & 0.620 \\
1984 & 63.5 & 73.0 & 3,174 & 0.642 & 0.673 & 0.577 & 0.631 \\
1985 & 64.0 & 74.1 & 3,340 & 0.650 & 0.682 & 0.586 & 0.639 \\
1986 & 64.5 & 74.9 & 3,502 & 0.658 & 0.689 & 0.597 & 0.648 \\
1987 & 65.1 & 75.6 & 3,965 & 0.668 & 0.697 & 0.614 & 0.660 \\
1988 & 65.6 & 76.4 & 4,114 & 0.677 & 0.703 & 0.620 & 0.667 \\
1989 & 65.9 & 77.2 & 4,213 & 0.682 & 0.709 & 0.624 & 0.672 \\
1990 & 66.3 & 78.0 & 4,691 & 0.688 & 0.715 & 0.642 & 0.683 \\
1991 & 66.6 & 78.8 & 4,822 & 0.693 & 0.725 & 0.47 & 0.689 \\
1992 & 66.9 & 79.6 & 5,105 & 0.698 & 0.734 & 0.656 & 0.696 \\
1993 & 67.3 & 80.4 & 5,562 & 0.705 & 0.743 & 0.671 \\
1994 & 67.7 & 81.2 & 5,280 & 0.712 & 0.750 & 0.662 & 0.706 \\
1995 & 68.1 & 82.0 & 5,620 & 0.718 & 0.755 & 0.672 & 0.708 \\
1996 & 68.5 & 82.3 & 5,999 & 0.725 & 0.755 & 0.683 & 0.715 \\
1997 & 68.9 & 83.2 & 6,463 & 0.732 & 0.758 & 0.696 & 0.721 \\
1998 & 69.3 & 84.0 & 6,486 & 0.738 & 0.763 & 0.696 & 0.728 \\
\hline \hline
\end{tabular}

Source: National Human Development Report Turkey 2001 (http://www.un.org.tr/undp/pdf/nhdr/tablo\%201.pdf)

Human Development Index: A composite index measuring average achievement by three basic dimensions of human development: a long and healthy life (life expectancy index), knowledge (education index), and a decent standard of living (GDP development). For details of how the indices are calculated see Technical Notes of

http://hdr.undp.org/reports/global/2004/pdf/hdr04_backmatter_2.pdf. 


\section{REFERENCES}

Bloom, D.E. and Williamson, J.G., 1998. 'Demographic transitions and economic miracles in Asia'. World Bank Economic Review 12(3): 419-455.

Blossfeld, H.P. and Rohwer, G., 2002. Techniques of Event History Modeling: New Approaches to Causal Analysis (second edition). Lawrence Erlbaum Associates, London.

Bongaarts, J., 2003. 'Completing the fertility transition in the developing world: The role of educational differences and fertility preferences'. Population Council, Policy Research Working Paper, No. 177.

Casterline, J.B., 2001. 'The pace of fertility transition: National patterns in the second half of the twentieth century'. Population and Development Review 27: 17-53.

Dündar, S.E.T., 1998. Social and Demographic Characteristics and Fertility Behavior of Main Language Groups in Turkey. Unpublished M.A Thesis, submitted to Hacettepe University Institute of Population Studies, Ankara.

Ergöçmen, B., 1997. 'Women's status and fertility in Turkey', in Fertility Trends, Women's Status, and Reproductive Expectations in Turkey: Results of Further Analysis of the 1993 Turkish Demographic and Health Survey. Hacettepe University Institute of Population Studies and Macro International Inc., Calverton, Maryland: 79-105.

Feeney, G. and Feng, W., 1993. 'Parity progression and birth intervals in China'. Population and Development Review 9 (1): 61-95.

Hacettepe University Institute of Population Studies (HUIPS), Ministry of Health, and Macro Int., 1994. 1993 Turkey Demographic and Health Survey. HUIPS, Ankara.

Hacettepe University Institute of Population Studies (HUIPS), Ministry of Health, and Macro Int., 1999. 1998 Turkey Demographic and Health Survey. HUIPS, Ankara.

Hacettepe University Institute of Population Studies (HUIPS), Ministry of Health, State Planning Organization, and European Union, 2004. 2003 Turkey Demographic and Health Survey. HUIPS, Ankara. 
Hancıoğlu, A. and Koç, İ., 1999. 'Demographic differentials and demographic integration of Turkish and Kurdish populations in Turkey'. Paper for the European Population Conference 1999, 30 August - 3 September 1999, The Hague, The Netherlands.

Hancioğlu, A., Koç, İ. and Bozbeyoğlu, A., 2000. 'Türkiye'de Türkçe ve Kürtçe anadil nüfuslarının demografik farklılaşma ve bütünleşme düzeyleri’. Paper for III. Ulusal Sosyoloji Kongresi, 2 - 4 Kasım 2000, Anadolu Üniversitesi, Eskişehir.

Hoem, J., 1996. 'The harmfulness or harmlessness of using an anticipatory regressor: how dangerous is it to use education achieved as of 1990 in the analyses of divorce risks in earlier years?' Yearbook of Population Research in Finland 33: 34-43.

Hoem, J., Prskawetz, A. and Neyer, G., 2001. 'Autonomy or conservative adjustments? The effect of public policies and educational attainment on third births in Austria'. Population Studies 55 (3): 249-261.

Human Development Report, 1996, (downloaded 15.02.2005). http://www.undp.org/rbec/nhdr/1996/summary/turkey.htm

Koray, S., 1997. 'Dynamics of demography and development in Turkey: implications to the potential for migration to Europe'. The Turkish Journal of Population Studies 19: 37-56.

Kleinbaum, D.G., 1996. Survival Analysis: A Self Learning Text. Springer-Verlag, New York.

Population Reference Bureau, 2004. 2004 World Population Data Sheet. PRB, Washington D.C.

State Planning Organization (SPO), 1993. Turkey, National Report to the 1994 International Conference on Population and Development. State Planning Organization Office, Ankara.

State Institute of Statistics (SIS), 1995. The Population of Turkey, 1923 - 1994: Demographic Structure and Development, With Projections to the Mid $21^{\text {st }}$ Century. State Institute of Statistics, Prime Ministry of Republic of Turkey, Ankara, Publication No. 1716.

State Institute of Statistics (SIS), 2003a. 2000 Census of Population: Social and Economic Characteristics of Population. State Institute of Statistics, Prime Ministry of Republic of Turkey, Ankara. 
State Institute of Statistics (SIS), 2003b. Population and Development Indicators. Web Site: http://nkg.die.gov.tr, September 7, 2003.

Taşıran, C., 1997. 'Econometric analysis of fertility dynamics in Turkey'. Paper for the $51^{\text {st }}$ Session of the International Statistical Institute, 18-26 August 1997, Istanbul.

Taşıran, C., 2000. 'Türkiye'de Doğurganlığın Dinamikleri', in Third Conference on Turkish Demography. HUIPS, Ankara: 123-152.

Timur, S., 1972. Türkiye'de Aile Yapısı. Hacettepe University, Ankara: D - 15.

United Nations, 1999. World Population Prospects, The 1998 Revision, Volume 1: Comprehensive Tables. ST/ESA/SER. A/177, Department of Economic and Social Affairs, Population Division, United Nations, New York.

UNDP, 2005. National Human Development Report, 2002, downloaded 15.02.2005. http://www.un.org.tr/undp/Human_report_eng.htm

Ünalan, T., 1997. 'Turkey's population at the beginning of the $21^{\text {st }}$ century'. The Turkish Journal of Population Studies 19: 57-72.

Van de Kaa, D.J., 1987. 'Europe's second demographic transition'. Population Bulletin 42 (1).

Weber, Max, 1961. 'Ethnic groups', in Talcott Parsons (ed.), Theories of Society. Free Press, New York. 